\title{
LA ECONOMÍA SOCIAL IBÉRICA: EL CASO DE LAS SANTAS \\ CASAS DE LA MISERICORDIA DE PORTUGAL COMO \\ INSTITUCIONES PARTICULARES DE SOLIDARIDAD SOCIAL ${ }^{1}$
}

\author{
POR \\ Antonio Juan BRIONES PEÑALVER, \\ Maria Paula LOPES CASTELAO ${ }^{2}$ y \\ Fernando CARDOSO DE SOUSA ${ }^{3}$
}

\section{RESUMEN}

Las organizaciones que conforman la Economía Social favorecen el desarrollo económico y colectivo, lo cual les facilita un gran reconocimiento institucional, tanto por la función que desempeñan como por su valorización por la actividad económica realizada, a favor del servicio de las necesidades sociales, la distribución equitativa de la renta, la creación de empleo y la corrección de los desequilibrios sociales. Esta economía todavía no ha sido concretizada por aquellas instituciones que son representativas del poder gubernativo y del rigor académico. No obstante, previo al establecimiento en común de un marco jurídico y económico, estas entidades de participación comunitarias, por su cercanía, inclusive regional, tienen tanto operaciones comerciales como otras actividades del ámbito público y privado. Por este motivo, es necesario establecer un cauce de comunicación y discusión de cuáles son las entidades que favorecen el desarrollo colectivo entre España y Portugal. En este trabajo, hacemos una exposición del marco conceptual de las entidades de la economía social ibérica (principalmente en España y Portugal), para centrarnos en conocer con más detalle la economía social portuguesa, a través del estudio de las Santas Casas de la Misericordia como

\footnotetext{
${ }^{1}$ Este trabajo está realizado en base a los resultados del proyecto de investigación de la Fundación SENECA, Agencia Regional de Ciencia y Tecnología, Murcia (2007-2010), a través de una ayuda a la consolidación de Grupos de Investigación (grupos precompetitivos); Referencia: 08606/PP/08.

${ }^{2}$ Antonio Juan Briones Peñalver, Maria Paula Lopes Castelao: Universidad Politécnica de Cartagena, Facultad de Ciencias de la Empresa. Región de Murcia-Cartagena (España). Direcciones de correo electrónico: aj.briones@upct.es, mpcastela@gmail.com

Instituto D. Alfonso III - El Algarve- Loulé (Portugal). Dirección de correo electrónico: cardoso_sousa@hotmail.com
}

REVESCO No 107 - Primer Cuatrimestre 2012 - ISSN: 1885-8031 - www.ucm.es/info/revesco

DOI: $10.5209 /$ rev_REVE.2012.v107.38745

Fecha de recepción: 04/04/2011

Fecha de aceptación: 17/05/2011 
Instituciones Particulares de Solidaridad Social. Mostramos su evolución histórica, el papel de las Santas Casas de la Misericordias, así como ciertas perspectivas y capacidades de respuesta en el futuro inmediato de estas entidades de la economía social portuguesa.

Palabras clave: Crecimiento, empleo, cooperativas, asociación, institución, Unión Europea (UE)

Claves ECONLIT: M100, M160, M290, L840.

\title{
IBERIA SOCIAL ECONOMY: "SANTAS CASA DA MISERICÓRDIA" - PARTICULAR INSTITUTIONS OF SOCIAL SOLIDARITY (IPSS) CASE STUDY
}

\begin{abstract}
:
Organizations operating within Social Economy environment, are contributing to accelerate collective and economic development which give them high levels of Institutional recognition. This recognition acknowledges the important role these institutions are playing in understanding social needs, solving social problems and ensuring increased levels of social equity and employability. Government organizations were not able to provide the activities/solutions offered by social economy organizations.
\end{abstract}

These type of organizations roles and responsibilities are including private, public and commercial activities. Thus, it's necessary to define discussion and communication channels about what are the entities that enhance collective development between Portugal and Spain. On this paper we have first presented the conceptual framework regarding Iberia social economy (especially Spain and Portugal) and then focus on Portuguese social economy knowledge: we will base our analysis on "Santas Casas da Misericordia", a particular institution of social solidarity with strong heritage within the Portuguese society.

Keywords: Development, employment, cooperative, associations, institutions, European Union (EU) 


\section{MARCO CONCEPTUAL DE LAS ENTIDADES DE LA ECONOMÍA SOCIAL}

La Economía Social (en adelante ES) la conocemos como la realidad social situada entre la economía pública y la economía capitalista, situándose como alternativa en favor de un desarrollo social, económico y colectivo. En este camino, existe cada vez más un gran reconocimiento institucional de la ES, así como de la articulación de políticas europeas específicas. Comenzó en los años ochenta, más concretamente en 1989 a través de la Comunicación de la Comisión al Consejo sobre "Las empresas de ES y la creación de un mercado sin fronteras". Otras dos instituciones comunitarias, el Comité Económico y Social Europeo (CESE) a través de Dictámenes y el Parlamento Europeo en los años 1990 con la creación de un "Intergrupo Parlamentario de la Economía Social", fueron algunas de las instituciones comunitarias, las que progresivamente reconocieron el importante papel de la ES en el desarrollo social y económico de Europa, así como el reconocimiento de las Entidades de la Economía Social (en adelante EES) como parte del Modelo Social Europeo.

Chaves (2008) examina las diferentes políticas económicas susceptibles de incidir sobre la ES como sector institucional, realizando un balance global de las políticas implementadas en la Unión Europea. La ES ha consolidado sectores tradicionales como la agricultura, el trabajo asociado, los servicios, el consumo y las actividades financieras y mutualistas. Monzón (2006) afirma que la Economía Social está formada por empresas y organizaciones situadas fuera del sector público y del sector privado capitalista, con profundas raíces históricas. Chaves, Monzon y Sajardo (2003) afirman que las funciones de las EES, son aquellas relativas a: 1) la producción de servicios vinculados con las necesidades de la sociedad; 2) la redistribución y estabilización; 3) la corrección de los desequilibrios del mercado de trabajo; 4) el pionerismo; 5) la potenciación del desarrollo económico endógeno; 6) el estímulo de la autonomía de los territorios; 7) la contribución al desarrollo sostenible; y, 8) la contribución al fomento de la democracia y el capital social.

La ES es un conjunto vivo, dinámico, muy rico por su diversidad y compuesto tanto por microasociaciones locales y pequeñas cooperativas, como por grandes grupos mutualistas y cooperativos (Saz y Carús, 2008). En definitiva el "movimiento cooperativo" constituye en la actualidad la columna vertebral de la economía social como sector institucional (Chaves, 1999:116). Las diferentes organizaciones que la conforman, en particular las organizaciones del ámbito asociativo, puede intervenir para impulsar la implicación de diversos agentes y 
grupos de interés afectados (Sanz y Carús, 2008). Por tanto, la ES se está proyectando como una institución necesaria para la estabilidad y sostenibilidad del crecimiento económico, la valorización de la actividad económica al servicio de las necesidades sociales, la distribución más equitativa de la renta, la creación de empleo y riqueza solidaria y la corrección de los desequilibrios en el mercado de trabajo.

La flexibilidad en el mercado de trabajo ha sido justificada por diversas razones y las EES no están exentas en ese cambio del modelo de estructura del empleo. Bettio et al. (2001) afirma que se incrementan los contratos precarios para que se creen más empleos, y además apunta que existe la necesidad de conciliar la vida laboral y familiar. La idea de flexibilidad laboral apareció en los años ochenta como elemento clave de superación de los graves problemas del empleo (Carrasco et al., 2003:75), situación parecida a la que hoy nos encontramos. Las formas de flexibilidad son diversas: ajustes de plantilla y horarios, variaciones salariales, adaptación a los cambios tecno-productivos, procesos de formación y cualificación permanente. En esta dinámica, lo cierto es que los cambios en la estructura de trabajo a favor de la pretendida flexibilidad laboral, ha dado lugar a la proliferación de formas nuevas de contratación que afectan a las EES, a su modelo de ocupación, e incluso a la vida de las personas que las integran.

La ES nace debido al aumento de las necesidades sociales, habiéndose fortalecido en los últimos años y teniendo una función económica importante en el seno de Europa, siendo reconocida, por la Comisión Europea, que sus organizaciones pueden contribuir para el equilibrio de mercado y para disminuir la tasa de desempleo. Asimismo, las EES han demostrado una capacidad para incrementar el nivel de cohesión social. En primer lugar ha contribuido a integrar social y/o laboralmente, tanto a las personas como a los territorios en desventaja; ello ha sido constatable con Asociaciones, Fundaciones, Empresas de inserción y otras Empresas sociales; el hecho del crecimiento del desempleo en Europa, es una de las principales razones de la importancia de la economía social y su contribución para la creación de empleo. En segundo lugar, la sociedad con las EES ha incrementado su nivel de cultura democrática, ha dinamizado su grado de participación social y ha proveído de capacidad de negociación a los grupos sociales excluidos del proceso económico.

Las áreas donde la economía social florece y se desenvuelve con mayor facilidad son en los servicios de proximidad y los servicios a la comunidad. Como servicios de proximidad 
se entiende las actividades realizadas anteriormente por la familia en el ámbito doméstico y que ahora son ejecutadas por terceros, pero necesitan de una proximidad y de una relación personal fuerte entre los que las usan y el prestador, tales como: servicios sociales (acogimiento de niños, jóvenes y necesitados de servicios a domicilio, apoyo a los desfavorecidos, tratamiento de ropa); servicios para mejorar la vida de las personas (habitación, seguridad, transportes colectivos, comercio de proximidad, revalorización de los espacios públicos).

La ES está desarrollándose a nivel mundial, creciendo y fortaleciéndose con la crisis del Estado de la Providencia y con el aumento de las necesidades sociales. A su vez, presenta dimensiones e identidades legales y jurídicas muy dispares según los países (no existe una uniformidad en el concepto de empresa de economía social). Así, existen países donde las empresas sociales son de gran importancia y ya están asentadas con identidad suficiente (por ejemplo España y Francia), y otros países como Portugal, donde están en crecimiento en los últimos años, y este sector se ha desarrollado en gran escala. En las empresas españolas (cooperativas y sociedades laborales) que adquieren formas societarias y jurídicas pertenecientes a la ES española, existe un claro dominio del factor trabajo, de las personas y del objeto social sobre el capital.

Gracias a ellas, algunas poblaciones y territorios se mantienen dinámicos, incluso muchas veces deben su sobrevivencia, gracias al desarrollo de estas formas asociativas híbridas, que adoptan fórmulas empresariales avanzadas y un modelo de gestión participativo y democrático. Sin embargo, la economía social portuguesa está legitimándose por las insuficiencias reveladas en la actividad del denominado tercer sector, que puede ser público o privado, debido al volumen de recursos que precisa, normalmente humanos. Para entender su importancia, es fundamental percibir de qué forma sus agentes se caracterizan, se organizan e intervienen en la esfera económica.

Saz y Carús (2008) afirman que las fortalezas de las organizaciones que conforman la ES, siguiendo el informe Sustainability (2005), se encuentran: (1) los valores resultan fundamentales para establecer vínculos y crear redes sustentadas en la credibilidad de la organización y en la confianza, (2) la comunicación y la conexión con el exterior representan una fortaleza significativa, (3) la creación de redes y el establecimiento de 
intercomunicaciones con todos los stakeholders (grupos de interés) es un activo en una sociedad globalizada e interconectada como la actual.

En los últimos años son muchas las llamadas de los investigadores a las EES como promotoras del cambio productivo y de transformaciones en el entorno, en particular por la existencia de mercados competitivos y globalizados que marcan las actuaciones empresariales en un contexto económico de competencia global, caracterizado por una intensificación de la competencia, por procesos de descentralización y deslocalización productiva, y la existencia de nuevos modos de actuación pública, con una clara tendencia a la desregulación y privatización progresiva de los servicios públicos. Por otro lado, la justificación de la concentración en el ámbito de las EES está relacionada con el logro de sinergias empresariales y el requerimiento al principio cooperativo de la "intercooperación" o cooperación entre firmas, formulado por la Alianza Cooperativa Internacional.

Las EES son capaces de aprovechar las oportunidades del mercado, y a la vez combinan las prioridades y necesidades de los recursos humanos, con sus resultados económicos, conjuntamente con el interés general de sus miembros y el Desarrollo Sostenible (Nogales, 2006). El término de Desarrollo Sostenible, nos lleva como primer referente al Informe Brundtland (1987), que lo define como "el desarrollo que satisface las necesidades de la generación presente sin comprometer la capacidad de las generaciones futuras para satisfacer sus propias necesidades (CMMAD, 1988).

La sociedad exige cada vez más a las empresas compromisos sociales y medioambientales que superan el ámbito estrictamente económico (De Nieves y Briones, 2009). Esto está provocando que las empresas asuman este tipo de responsabilidades y adopten prácticas de Responsabilidad Social Empresarial (RSE) dirigidas a satisfacer las expectativas de los diferentes grupos de interés, máxime cuando las mismas pueden explicar, en buena medida, el logro de ventajas competitivas. Puesto que las EES no escapan a esta situación, deben de enfatizar sus comportamientos en actuaciones de RSE. Su contribución al desarrollo sostenible del territorio es muy significativa (Mozas y Bernal, 2006; Nogales, 2006). Por tanto, ese desarrollo sostenible adicionalmente, debe llevar consigo alternativas innovadoras y nuevas formas de pensar en base a la creatividad, que hagan que los avances contribuyan al desarrollo económico y al bienestar social, pero a la vez no supongan amenazas para las relaciones sociales y medioambientales (Arcas y Briones, 2009). 
A tal fin de su existencia, las EES en una situación de crisis como la actual, se enfrentan al desafío de integrar en sus actuaciones procesos productivos eficientes y objetivos de bienestar social. Los actores de la EES deben acometer sin demora el desarrollo de estrategias competitivas, acordes a las exigencias del mercado, que les permitan configurarse como instrumentos útiles para el bienestar de sus miembros y el fortalecimiento de la cohesión social.

\section{INSTITUCIONES Y AGENTES DE LA ECONOMÍA SOCIAL EN PORTUGAL}

El concepto de ES en Portugal sigue la corriente europea, definiéndose como una vía autónoma, ni pública ni privada, y cuya intervención en el mercado se basa en valores y principios que definen un modelo organizativo específico y vocacional para la supremacía del hombre sobre el beneficio o lucro. La ES portuguesa ha tenido una dinamización evidente en las últimas décadas, siendo notorias las insuficiencias comparándolas con la cobertura del sector público, siendo el sector privado, el que legitima las actividades de la ES. Fuera emplean un número significativo de personas, y comparándolo con países del sur de Europa, como España e Italia, en Portugal el denominado Tercer Sector se encuentra bajo valores de mejora de los países de la Europa Occidental.

Este Tercer Sector en Portugal intensifica su participación para combate de la pobreza y de la exclusión social. Un área particular de actuación en este campo de la ES, pretende el desarrollo de acciones y de proyectos innovadores, tanto a nivel de contenidos y de modelos de trabajo adoptados, a través de colaboraciones y de la explotación de redes colaborativas (Samartinho y Faria, 2009).

En el estudio efectuado por Barros (2003), y cuyo objetivo fue describir la estructura del tercer sector y evaluar la importancia cuantitativa de las organizaciones que operan en el mismo, las organizaciones fueron agrupadas en tres categorías: Cooperativas; $\underline{\text { Asociaciones }}$ no solidarias (organizaciones no gubernamentales / fundaciones y mutualidades no benéficas / organizaciones pastorales eclesiásticas); Instituciones de solidaridad social (misericordias / fundaciones de solidaridad / mutualidades de solidaridad / asociaciones de solidaridad). 


\subsection{Las cooperativas}

Las cooperativas son personas colectivas autónomas que velan, a través de la cooperación y ayuda de sus miembros, sin fines lucrativos, para la satisfacción de las

necesidades y aspiraciones económicas, sociales y/o culturales de sus asociados. Las cooperativas, son organizaciones voluntarias, de libre adhesión y abiertas a todas las personas que pretendan ser miembros y utilizar sus servicios.

Se caracterizan por la participación económica de sus miembros y por la gestión democrática, que deberá ser asegurada en el caso de que se establezcan acuerdos con otras organizaciones públicas o privadas, o recojan capitales externos. Los principios de educación, formación e información son sus valores, bien como la intercooperación y el interés por la comunidad.

Oliveira y Simöes (2009) afirman que las cooperativas socialmente emprendedoras serán fundamentales para enfrentarse al desemplo estructural que afectan a las economías locales, particularmente en regiones deprimidas, en la medida que contribuyen a la valorización del territorio, también promoverán la construcción de un medio socialmente innovador.

El sector cooperativo portugués está organizado en doce ramos específicos, con legislación propia y de acuerdo con su objeto principal: agrícola, artesanos, comercialización, consumo, crédito, cultura, enseñanza, edificación y construcción, pesca, producción obrera y de servicios, y solidaridad social. En opinión de Barros (2003), este sector es el de mayor potencial de crecimiento en Portugal y está constituido por 2.740 organizaciones, que recogen a 190.279 socios y que emplean a 35.480 personas. Debemos indicar finalmente, que las cooperativas pueden pedir equiparación a las instituciones de solidaridad social, y en ese caso, esa designación les posibilita favorecer la persecución de sus objetivos.

\subsection{Otras asociaciones}

Además de las cooperativas, existen otros organismos pertenecientes al tercer sector y que no se encuadran en la categoría de las Instituciones Particulares de Solidaridad Social (IPSS). Esas asociaciones, dado su amplitud y dispersión, han sido menos estudiadas en 
Portugal, verificándose una ausencia de datos que las incluya a todas (Ferreira, 2000). Hablamos de las ONG -Organizaciones no gubernamentales. Las áreas fundamentales de intervención son la cooperación y la educación para su desarrollo, bien como la ayuda humanitaria y de urgencia.

Estas organizaciones movilizan, en general, la opinión pública y promueven la participación de la sociedad civil para mejorar determinados aspectos de la sociedad, tendiendo su mayoría, a una actividad solidaria y de cooperación con los países más pobres.

\subsection{Las Instituciones Particulares de Solidaridad Social (en adelante IPSS)}

La IPSS son empresas sociales, que en general ofrecen servicios de proximidad diversificados y organizados en diferentes unidades de servicios (Lópes y Cardoso, 2009). La función de estas organizaciones es proveer de bienes, servicios y equipamientos sociales, entendiéndose con la propagación de valores de solidaridad. De hecho, estas instituciones tienden a concentrar su actividad en la áreas sociales, culturales, de investigación en el ámbito de la sociedad civil, por eso, vamos a centrar la investigación en las IPSS que persiguen su actividad en el dominio social, una vez que, después de ser las que tienen más representatividad en la Economía Social Portuguesa, y en esa área se encuadran las Santas Casas de la Misericordia (ver la tabla 1).

Tabla 1. Formas jurídicas de las IPSS

\begin{tabular}{lll}
\hline \multicolumn{1}{c}{ Naturaleza } & \multicolumn{1}{c}{ Tipos } \\
\hline Asociativa & - & Asociaciones de solidaridad social \\
& - & Asociaciones de voluntarios de acción social \\
& - & Hermandades de la Misericordia o Santas Casas de la \\
& & Misericordia \\
\hline Fundacional & - & Fundaciones de solidaridad social \\
& - & Instituciones creadas con fines religiosos \\
\hline
\end{tabular}

Las IPSS pueden ser de naturaleza asociativa, asumiendo una forma de asociaciones de solidaridad social, asociaciones de voluntarios de acción social, asociaciones de urgencias mutualistas o asociaciones mutualistas, Hermandades de la Misericordia o las Santas Casas de la Misericordia, de naturaleza fundacional, adoptando jurídicamente la forma de fundaciones de solidaridad social y centros sociales parroquiales, o otras instituciones creadas por 
organizaciones religiosas. Son reguladas por ley, y están a cargo de una dirección, independiente del Estado, en conjunto con una asamblea general y un consejo fiscal. Estas organizaciones se integran en el ámbito de las personas colectivas de utilidad pública, persiguen objetivos de interés general, en estrecha colaboración con el Estado, que les reconoce el acceso a diversos beneficios, especialmente de naturaleza tributaria.

Siguiendo la Procuradora General del Distrito de Lisboa (2006), están registradas 4.634 instituciones particulares de solidaridad social a nivel nacional, y las principales respuestas sociales proporcionadas por estas instituciones son dirigidas para personas de avanzada edad, la infancia y juventud, las dificultades familiares, toxicó dependencia, los indigentes y sin hogar y de los cuidados médicos.

Por último, es importante referirse a la Unión de las Misericordias Portuguesas (UMP), creada en 1976, surge debido a la secuencia de las transformaciones sociales que tuvieron origen el 25 de abril de 1974. La Unión de las Misericordias Portuguesas (UMP) tienen como objeto orientar, coordinar, dinamizar y representar a las Santas Casas de la Misericordia, defendiendo sus intereses, organizando servicios de interés común y fomentando entre ellas los principios que fueran en base a la cristiandad de su origen y determinaran el espíritu solidario de su acción, estimulando la fraternidad y del desarrollo y buena relación entre las Casas de la Misericordia. Se rigen por estatutos propios y gozan de personalidad jurídica civil y canónica, y una asociación formada por todas las Santas Casas de la Misericordia que votarán los estatutos.

Actualmente existen cerca de 400 Santas Casas de la Misericordia, en el continente y en las regiones autónomas de Madeira y de las Azores, con el apoyo de la fundación y recuperación de las Misericordias en los países de lengua portuguesa (Angola, Santo Tomé, Mozanbique y Timor-Leste), bien las comunidades emigrantes dispersas por la diáspora (Luxemburgo, París y Pretória), estando en perspectiva una fundación de nuevas Misericordias en Berlin, Joanesburgo, Buenos Aires, Caracas, San Francisco y Newark. A nivel europeo, la Unión de las Misericordias Portuguesas (UMP) integra la Unión Europea de las Misericordias, fue promotora y cofundadora, a nivel internacional de la Confederación Internacional de las Misericordias. 


\section{ANÁlisis PARTicular DE LAS IPSS- LAS SANTAS CASAS DE LA MISERICORDIA}

Es muestro objetivo analizar el papel de las instituciones Particulares de Solidaridad Social (IPSS), aquí ejemplificado por las Santas Casas de la Misericordia. El análisis particular de las IPSS permite hacer una distinción entre estas instituciones y los restantes agentes, que al no funcionar como empresas serán esencialmente financiadas por donativos, cotizaciones y apoyos estatales, sin olvidar que cuentan con el trabajo del voluntariado. Con naturaleza asociativa o fundacional estas instituciones, además de abastecerse de bienes y servicios sociales, tienen también por función propagar valores de solidaridad. Este es el caso de las Santas Casas de la Misericordia que a pesar de tener una tradición multisecular, presentan hoy una reducción de su número, por fuerza de su peso institucional. Sin embargo, han crecido en actividades y en patrimonio, aunque con algunas disparidades entre instituciones.

\subsection{Evolución histórica de las Misericordias}

La fundación de la primera Misericordia Portuguesa, es atribuida a la reina Dña. Leonor; surge en el contexto de grandes turbulencias económicas y sociales, cuyo principal marco social y económico, fueron los descubrimientos. El principal objetivo fue crear una organización capaz de integrar a las pequeñas organizaciones de solidaridad ya existentes, con una perspectiva más amplia, capaz de alcanzar todo el reino. El modelo seguido, inspirado en la institución Italiana (Misericordia de Florencia, fundada en 1240) acabo por perseguir misiones y objetivos más amplios.

Una de las características fundamentales de las Santas Casas de la Misericordia es su forma asociativa de hermandad que de acuerdo con los compromisos de realización de las obras de misericordia, tienen por objetivo beneficiar a otros y no a los propios hermanos, como sucede en las asociaciones mutualistas.

El compromiso de la Misericordia, fue establecido en su fundación, y está incluido desde el primero hasta los actuales. En este compromiso, están integrados los estatutos que rigen la institución, estando definidos entre otros, su denominación, naturaleza, organización, 
finalidad, condiciones de admisión de los hermanos, sus derechos y deberes, además del régimen financiero y el cuerpo gerente.

El modelo organizacional adoptado refleja los mecanismos del poder local y las diferencias sociales existentes, las cuales pueden ser ejemplarizadas a través del análisis del modelos de reclutamiento y gestión (de sus miembros) adoptados. Son admitidos hermanos de primera categoría (hidalgos o nobles) y hermanos de segunda categoria (artesanos, comerciantes, militares). Este último estaba vedado para los cargos de la jefatura más importantes (como los proveedores, escribanos o tesoreros) y apenas tenían acceso a sentarse en la mesa -órgano colegial de la cofradía- y ejercer alguna mayodormía en colaboración con hermanos nobles.

La Misericordia era administrada por un gerente, nueve consejeros, un escribano y dos mayordomos; los miembros de la mesa, en número de doce, debían ser obligatoriamente maestros artesanos, y miembros del alto clero y de la nobleza. La figura del gerente tiene un papel central en la gestión de la Misericordia, en la distribución de los cargos y en su funcionalidad.

Las Misericordias adoptaron un modo de estar en la Iglesia y en la sociedad civil diferente al tradicional. Estas fueron desde el principio, instituciones regias de índole devocional laica con independencia de las autoridades eclesiásticas. Fue esa independencia la que le concedió a las Misericordias algunas originalidades. La ausencia de tutela eclesiástica, en contraposición con la protección real, que se fue construyendo desde los primeros años, y transformó el caso portugués en un caso único en el panorama europeo.

De las alteraciones estatutarias ocurridas en 1945, las cuales desdoblaron las Santas Casas en dos instituciones- una laica, destinada a ejercer acción social, y otra hermandad, destinada a prestar asistencia religiosa y moral. Con los Estatutos de las IPSS en 1979, se puso término al régimen dualista y se devolvió la unidad a la hermandad. Con base en esta publicación, el secretario nacional de Unión de Misericordias Portuguesas, preparo con el apoyo de técnicos especializados, un compromiso normativo con base al cual, las Santas Casas de la Misericordia se rigen en la actualidad, con las debidas adaptaciones, de acuerdo con las exigencias y las especificaciones de cada institución. 
Fue en 1498 cuando se inició en Portugal con la creación de la Misericordia de Lisboa, un movimiento de edificación de estas cofradías por todas las ciudades y villas del reino (Lobo, 2006). A partir de 1562 y hasta mediados del siglo XX, tendrán las misericordias la responsabilidad por la administración de la red hospitalaria, vocación que no constaba en los compromisos iniciales. No obstante, el haber continuado promoviendo la visita a presos, financiar rescates a cautivos, conceder dotes de casamiento y ocuparse de los pobres, su trabajo de mayor envergadura paso a ser el hospital. En las misericordias de cada localidad fueron incluidos los establecimientos locales de asistencia social y hospitalaria, poniendo fin a la pulverización y duplicación de instituciones.

Este proceso de integración fue acompañado por la preocupación de garantizar una mayor eficacia organizacional, a través de escoger con cuidado a los administradores cualificados, atendiendo a su preparación e idoneidad, y no a su clase social. Sin embargo, las Santas Casas de las Misericordias, al igual que el Ayuntamiento y el Ejército se transformaron en entidades de actuación social, que consentían el tráfico de influencias, la formación de redes de poder y la renovación de los gerentes, contando con las familias influyentes de poder concentrado y gran parentesco (Lobo, 2006).

Las misericordias se convirtieron en cofradías burocráticas y de organización administrativa compleja y su proliferación aconteció por todo el territorio nacional, incluidos los archipiélagos de Madeira y de las Azores. En relación a la expansión marítima, las misericordias representan ahora un importante papel en el auxilio a los pueblos subdesarrollados, prestando auxilio a los marineros y soldados portugueses. Estas instituciones, que se caracterizan por una red descentralizada que acompañó la prolongación del imperio, son únicas en la polivalencia de sus actividades. Si bien es cierto que algunas de estas instituciones han desaparecido en la secuencia de varios acontecimientos históricos, la expansión de las misericordias, prueba la eficiencia de una vasta red que rodeaba Portugal y sus imperios. Es de destacar el caso de Brasil, donde surgieron por todo el territorio agregadas a un hospital; y el caso de las Misericordias de Oriente que cuidaban también de los intereses económicos de los herederos de aquellos que fallecían en este territorio, se encargaban de transferir sus herencias a través de las misericordias del continente, por tanto, movían una gran cantidad de dinero. 
Ahora, conforme ya referimos, existen Misericordias en otros países, normalmente en Italia, sin embargo ninguna de ellas prevé en sus estatutos la realización de la totalidad de las obras de misericordia: las instituciones italianas prestan esencialmente servicio de emergencia médica, de ambulancia y de donación de sangre, se encargan también de los funerales de los pobres. Las Santas Casas- denominación particular de las misericordias portuguesas- son dotadas de una polivalencia intemporal, que permitió responder a las sucesivas necesidades sociales en la evolución de la historia.

La organización de las prácticas de asistencia a los pobres, ahora local o regional, estuvo encuadrada en un sistema uniforme que unía autonomía local con los intereses del patrimonio del poder central. Esa unión permitió la propagación de estas instituciones por todo el imperio, traspasando un nivel meramente regional, a diferencia de lo que sucedió en muchas zonas de Europa. Por otro lado, el compromiso con el que fueron dotadas en su origen, les concede características únicas, confiriéndole finalidades amplias y diversas que no se encuentran en ninguna otra institución de solidaridad social.

A lo largo de los siglos estas instituciones acumularon importantes riquezas, que contribuyeron en la creación de un valioso patrimonio (las Santas Casas eran poseedoras de una parte considerable del patrimonio cultural portugués, contabilizándose 35 museos, 80 plazas de toros, 9 galerías de arte, además de centenas de iglesias).

Las principales fuentes de financiación referidas a lo largo de la historia, son las donaciones y concesiones reales; anexiones de hospitales y capillas, transportando tierras y otros bienes; asimismo cuentan con sus propios medios de recogida de fondos (siendo las limosnas recogidas por devotos, por donaciones individuales ofrecidas por particulares, y además, por limosnas del Rey). Estas instituciones posibilitaban también un conjunto de operaciones financieras que traspasaban los simples préstamos jurados; servían de fuente de crédito para las grandes casas señoriales, o para la propia corona en situación de emergencia, y operaban trasferencias de capital encontrando los herederos de los portugueses fallecidos en ultramar.

Es de destacar la concesión de la explotación de los juegos sociales (que se remonta 1873) normalmente la lotería clásica, popular, totobola y totoloto, que fue creada en 1961 por el departamento de Apuestas Mutuas Deportivas -Totobola, que ha permitido la construcción, 
organización y actualmente manutención del Centro de Medicina de Rehabilitación de Alcoitão, y de la Escuela Superior de Salud de Alcoitão).

En 1867 surge además una ley que permitió a las Santas Casas poseer establecimientos bancarios. A pesar de todo, la ley de Desamortización de los Bienes de Mano-Muerta, publicada en 1866, afecto profundamente a las fuentes de derechos de origen patrimonial de las misericordias (como a otras instituciones de caridad) ya que obligaba a las instituciones a vender en subasta pública la mayor parte de su patrimonio y a convertir el valor en obligaciones del estado que se desvalorizaban rapidamente, lo que afecto a toda la red hospitalaria administrada por las misericordias.

Al final del siglo XIX, marcado por la revolución industrial, la concentración de las poblaciones en las ciudades, la modernización del aparato del Estado y la construcción de una economía capitalista, el Estado comienza en toda Europa, a responsabilizarse, junto con las instituciones de caridad, de los tratamientos de los enfermos. En este momento, se desenvuelve un movimiento de construcción o ampliación de los hospitales, las misericordias que no tenían el apoyo del Estado no estaban en condiciones de proceder a la modernización tecnológica y organizacional de la red hospitalaria que administraban hacia varios siglos.

Fue el período final del Estado Nuevo, ahora descapitalizadas, las misericordias llevaran a cabo gran parte de las construcciones y remodelaciones de los hospitales, por beneficiarse de importantes coparticipaciones del Presupuesto General del Estado, apoyo de la Fundación Gulbenkian y de otros fondos, normalmente recibidos de la Totobola.

Después de Marzo de 1975, acontecen profundas transformaciones en los procesos políticos, con la nacionalización de sectores significativos de la industria, la nacionalización total de los bancos y de las aseguradoras, la expropiación de las tierras en el Alentejo, la creación de comisiones de trabajo, la autogestión de las empresas, la creación de cooperativas y de comisiones de trabajadores.

En este contexto de lucha política (inestabilidad gubernamental), y de grandes conflictos sociales, el Estado fue llamado a crear nuevas instituciones y a producir normas que anunciaran nuevas políticas sociales. Así, en 1974, la Secretaria de Estado de Salud divulgo un plan de reestructuración del sistema hospitalario del país, el cual preveía el 
traspaso de los hospitales del concejo a hospitales del distrito y la conversión de los restantes en unidades de internamiento. La puesta en funcionamiento de ese plan, oficializó a nivel total y gratuito los hospitales (no obstante la propiedad de los inmuebles continuó perteneciendo a las misericordias que debían administrar los bienes afectados por legados religiosos debiendo todavía entregar los rendimientos al Estado).

La oficialización se extendió a los hospitales del concejo, incluyendo los que pertenecían a las misericordias, previniéndose todavía la extinción de las Misericordias en el caso, que la sucesión de normalización de sus hospitales, se verificase que ellas no conseguían garantizar la manutención de ningún establecimiento o actividad integrada en la política social aprobada por el Gobierno. Con la "oficialización" de los hospitales distrito y concejos pertenecientes a las misericordias, se refuerza de forma significativa la responsabilidad del Estado hacia los hospitales. El Estado asume así el carácter estratégico de este sector, queriendo que los recursos financieros empleados, puesto que casi todos eran asumidos por el Estado, posibiliten la dinamización de una política pública enfocada hacia las unidades hospitalarias con control estatal.

La Unión de las Misericordias Portuguesas (UMP) es un organismo creado en 1976, como ya referimos anteriormente, siguiendo las transformaciones sociales sucedidas tras la Revolución, normalmente la nacionalización de los hospitales de las misericordias. La UMP, se rige por estatutos propios, es una asociación formada por todas las Santas Casas de la Misericordia que votaron los estatutos (cerca de 400), y tienen por objetivo coordinar y representar las Santas Casas, defendiendo sus intereses.

Esto ha supuesto un esfuerzo colectivo de las Misericordias, que abrazado a su existencia y determinación de supervivencia, se configuran con una estructuración jurídica en el panorama social de la época. En 1980, a través de la Resolución del Consejo de Ministros, fue manifestada la intención de solucionar el contencioso creado con las misericordias y se inicio, después de varios despachos y Decretos-ley, la reparación de los prejuicios causados a las Santas Casas y otras instituciones particulares, cuyos hospitales habían sido nacionalizados. 


\subsection{El papel de las Misericordias en la actualidad}

Actualmente, las Santas Casas de la Misericordias colaboran con los fines del Estado e intervienen en la resolución de problemas concretos, realizando estas actividades cuando es necesario, en cooperación con instituciones públicas. Por otro lado, continúan con acciones religiosas y colaboran en los fines de la iglesia. No obstante, surge de la iniciativa de los particulares y obedece a las leyes generales de la iglesia y del Estado, y la gestión de esas instituciones es de exclusiva responsabilidad de aquellos que la constituyen, siendo la designación de los titulares de los cuerpos sociales responsabilidad de la Asamblea-General de los Hermanos.

Los cuerpos sociales de una Santa Casa de la Misericordia, son voluntarios y se constituyen en una Asamblea-General, una Mesa administrativa y un consejo Fiscal. Jerárquicamente, la Unión de las Misericordias federa todas las Misericordias del país, y es constituida por una Asamblea-General, un consejo Fiscal, un secretariado nacional, un consejo nacional y secretariados regionales distribuidos por 20 concejos, normalmente el de Faro, representado por el proveedor de la santa Casa de la Misericordia de la ciudad.

Para comprender mejor el papel actual desempeñado por estas instituciones en Economía Social Portuguesa, será importante conocer algunos indicadores:

A) Distribución de las Misericordias en el territorio nacional: existían en 1997 en el territorio cerca de 388 unidades (ver tabla 2), estando cuatro de ellas inactivas en el año de referencia, con una mayor incidencia en la zona centro del país.

Tabla 2. Distribución de las Misericordias, según regiones, año 1997

\begin{tabular}{lcc}
\hline \multicolumn{1}{c}{ Región } & Número & \% \\
\hline Norte & 73 & $18,8 \%$ \\
Centro & 136 & $35,1 \%$ \\
Lisboa e Vale do Tejo & 61 & $15,7 \%$ \\
Alentejo & 68 & $17,5 \%$ \\
Algarve & 23 & $5,9 \%$ \\
Azores & 22 & $5,7 \%$ \\
Madeira & 5 & $1,3 \%$ \\
Total & $\mathbf{3 8 8}$ & $\mathbf{1 0 0 , 0 \%}$ \\
\hline
\end{tabular}

Fuente: Eiras (2002) 
B) Principales actividades desempeñadas en las comunidades: las actividades de las Santas Casas están muy orientadas hacia la infancia (63\%) y tercera edad (85\%). Ahora el apoyo a la infancia parece estar fuertemente enraizado en la actividad de estas instituciones por todo el país, es el trabajo con los ancianos el que se rebela, casi unánimemente, como la actividad preferencial.

Tabla 3. Actividades de las Misericordias, año 2000

\begin{tabular}{lccc}
\hline \multicolumn{1}{c}{$\begin{array}{c}\text { Área de } \\
\text { Actividad }\end{array}$} & $\begin{array}{c}\text { \% de Misericordias } \\
\text { activas en cada área }\end{array}$ & $\begin{array}{c}\text { Media de } \\
\text { Usuarios }\end{array}$ \\
\hline Salud & $17 \%$ & 1875 & 37 \\
Educación & $18 \%$ & 386 & 20 \\
Infancia & $63 \%$ & 620 & 65 \\
Juventud & $23 \%$ & 360 & 22 \\
Familia & $17 \%$ & 1500 & 23 \\
Tercera Edad & $85 \%$ & 610 & 120 \\
Invalidez & $8 \%$ & 160 & 4 \\
Pobreza & $22 \%$ & 180 & 7 \\
Minorias Étnicas & $4 \%$ & 50 & 1 \\
Empleo & $16 \%$ & 150 & 7 \\
Otras & $9 \%$ & 300 & 8 \\
\hline
\end{tabular}

C) Número medio de usuarios por trabajador: este indicador revela grandes diferencias en el modelo organizacional adoptado por cada una de las Misericordias existentes en el país, por ejemplo, se constata que el 50\% de las Misericordias tienen, un máximo de seis usuarios por trabajador, y tres tienen más de 150 usuarios por funcionario.

D) Principales fuentes de financiación: el Estado, a través de la elaboración de protocolos, es la principal fuente de financiación de las Misericordias (48\%), y la venta de servicios contribuye en media para generar un cuarto de los ingresos. Los donativos y los legados constituyen aproximadamente el $11 \%$, representando el $9 \%$ y el $2,5 \%$ de los ingresos respectivamente.

E) Evolución de la actividad realizada por estas instituciones: de acuerdo con algunos estudios existentes podemos referir que la mayoría de estas instituciones (91\%), parecen haber aumentado su actividad en los últimos cuatro años, y ninguna hace referencia a una disminución de la actividad. Las razones aportadas para esa evolución fueron el aumento de las demandas (77\%) y la celebración de acuerdos con el Estado (78\%). Los resultados también revelan que las Misericordias establecen parcelas preferentemente con el Estado, las alcaldías, otras misericordias e IPSS. 
Dentro del modelo organizacional adoptado por estas instituciones, conviene salvaguardar la especificidad de la Santa Casa de la Misericordia de Lisboa que se caracteriza por ser una persona colectiva de utilidad pública administrativa, con una gestión interna distinta de las restantes - normalmente debido al factor de que sus órganos sociales están sobre la tutela de dos ministerios - y cuyas áreas de intervención son, esencialmente, la familia, maternidad y infancia, menores desprotegidos, personas mayores, situaciones de carencias graves, cuidados de salud primarios y diferenciados.

La oferta de servicios y equipamientos de apoyo a los niños y jóvenes en la Santa Casa de la Misericordia de Lisboa es muy amplia y abarca una población de cerca de cinco mil niños y jóvenes, como es la oferta de cuidados de salud, de los cuales se destacan los Servicios de salud de San Roque, constituidos por una decena de unidades que prestan cuidados de salud primarios por la diversas áreas socialmente desfavorecidas. Esta institución emplea cerca de dos mil personas y sus principales fuentes de ingresos son las que provienen de la gestión de su patrimonio y las de la parte correspondiente a los resultados líquidos y financieros de la explotación exclusiva de los juegos sociales (loteria, totobola y totoloto, entre otros).

\subsection{Conclusiones: perspectivas y capacidades a los desafíos futuros}

Las misericordias, representan un modelo organizacional, integrado en el cuadro jurídico de las IPSS, lo cual demuestra una extraordinaria capacidad de adaptación a los diferentes contextos socio económico vividos a lo largo de cinco siglos de historia. Esta institución desempeña un papel social extremadamente importante en el desarrollo de las comunidades en el territorio nacional y en las colonias.

Relativo al modelo de organización interno adoptado por estas instituciones, es de considerar que a pesar de prolongarse las formas de discriminación social, al admitir hermanos de primera categoría (hidalgos y nobles) y hermanos de segunda categoría (artesanos, comerciantes, militares) se atenuaban tales diferencias en función de su objetivo solidario, organizándose en fundación de tres líneas maestras: creatividad organizacional, orientación integradora y coordinada y fuerte preocupación técnica y administrativa. 
Esa estructura organizacional se acentuó a partir del siglo XVI hasta el siglo XX, con la responsabilidad de la administración de la red hospitalaria. Las Misericordias se convierten en instituciones burocratizadas y de organización administrativa compleja y su proliferación se acentúa por todo el territorio nacional, acumulando importantes riquezas, que contribuían a la creación de patrimonios valiosos, incluidos establecimientos bancarios.

Mientras tanto, la publicación de la Ley de Desamortización de los bienes de ManoMuerta, en 1866, afecto profundamente a las fuentes de ingresos de origen patrimonial de las Misericordias, agravándose posteriormente su situación con la revolución del 25 de Abril del 1974, perdiendo los rendimientos de los hospitales. Sólo en 1980, fueron restituidos los bienes expropiados y aceptado el proceso de indemnizaciones.

En 1997, existían cerca de 400 unidades, asociadas en torno a un nuevo modelo organizacional, poseyendo un patrimonio considerable, con una actividad muy orientada hacia la infancia y la tercera edad y con grandes diferencias cuanto al número de trabajadores. En cuanto a su financiación actual, el Estado asume mas de la mitad de los gastos, quedado un cuarto para la venta de servicios y los restantes para donativos y legados a excepción de las Misericordias de Lisboa con estatuto y características especiales.

La presión de las comunidades y la constatación de la insuficiencia de las respuestas originaran un aumento significativo de servicios, tradicionales (como por ejemplo guarderías y hogares para la tercera edad), tanto innovadores (como por ejemplo, unidades de prevención y tratamiento de toxico dependientes). Con todo, en presencia de nuevos desafíos colocados por el medio, algunas unidades pertenecientes a esta institución han demostrado dificultades de respuesta y anticipación.

Manteniendo la importante misión y visión que las guió durante mas de quinientos años, las Santas Casas han demostrado un nivel bajo de liderazgo y dificultades en áreas de tecnología, pareciendo necesitar de un cuerpo de profesionales cualificados y competentes, y de un cuerpo dirigente que, ahora voluntario, perciba que la gestión de estas instituciones implica una variedad de conocimientos técnicos y comportamientos que ellas muchas veces no poseen. 
La crisis del Estado-Providencias, el envejecimiento de la población, y el ritmo de crecimiento de la exclusión social de algunos grupos de población, pueden representar un desafió para estas instituciones, si supiesen gestionar sus recursos y adaptarse a las nuevas realidades.

Las Misericordias fueron instituciones con extraordinaria importancia en la lucha contra la pobreza, la orfandad, la enfermedad, la invalidez, la vejez y la muerte desde la época de los descubrimientos. Por ello, manteniendo bien altos los valores y la lógica de constitución que están en el origen de estas instituciones, es bien probable que las Misericordias se puedan constituir como organizaciones con clara vocación competitiva en relación a las restantes IPSS, cuando consigan equilibrar esos valores con las necesidades actuales de gestión, en lo referente a la presentación de resultados, muestra indicadores objetivos y la presentación de servicios sociales con carácter innovador y con progresiva independencia financiera del Estado e ideológica de la Iglesia.

\section{BIBLIOGRAFÍA}

ARCAS, N., y BRIONES, A.J.: "Responsabilidad Social Empresarial de las Organizaciones de la Economía Social. Valoración de la misma en las empresas de la Región de Murcia”, CIRIEC-España, Revista de Economía Pública, Social y Cooperativa, nº 65, 2009, pp. 143-161.

BARROS, C. P.: Cooperativismo e economia social em Portugal: Caracterização e análise. In Barros, C. P. \& Santos, J. G. (Eds). Cooperativismo, emprego e economia Social. Lisboa: Editora Vvulgata, 1999.

BARROS, C. P.: Portugal. In Campos, J.M. et al (Eds). El tercer sector no lucrativo en el Mediterráneo. Valencia: CIRIEC España, 2003.

BETTIO, F. et al.: Género y flexibilidad en el empleo en la Unión Europea. En Rossilli, M. (coord.): Políticas de género en la Unión Europea, Madrid, Narcea, 2001.

CAPELA, J.V.Eiras: "Vila Nova de Cerveira. Elites, poder e governo municipal". Braga, Universidade de Minho, 2002, pp. 57-65.

CARRASCO, C. et al.: Tiempos, trabajos y flexibilidad: una cuestión de género, Madrid, Instituto de la Mujer, 2003. 
CHAVES, R.: "La economía social como enfoque metodológico, como objeto de estudio y como disciplina científica”, CIRIEC-España, Revista de Economía Pública, Social y Cooperativa, $\mathrm{n}^{\circ} 33,1999$, pp. 115-140.

CHAVES, R.: "Public Policies and Social Economy in Spain and Europe", CIRIEC-ESPAÑA, Revista de economía pública, social y cooperativa, no 62, special issue, 2008, pp. 35-60

CHAVES, R.; MONZÓN, J.L. y SAJARDO, A.: Elementos de Economía Social. Teoría y Realidad, Universidad de Valencia, 2003.

CMMAD (Comisión Mundial del Medio Ambiente y del Desarrollo) : Nuestro Futuro Común (Informe Brundtland), Alianza Editorial, Madrid, 1988.

COMISIÓN EUROPEA: Comunicación sobre el Sexto Programa de Acción de la Comunidad Europea en materia de Medio Ambiente, COM (2001) 31 final.

DE NIEVES, C., y BRIONES, A.J.: "Las empresas de economía social y su relación con las instituciones: colaboración con la universidad en asuntos medioambientales", CIRIECEspaña, Revista de Economía Pública, Social y Cooperativa, nº 65, 2009, pp. 85-111.

FERREIRA, S. D.: As organizações do terceiro sector na reforma das políticas publicas de protecção social. Dissertação de mestrado (não publicado). Coimbra: Faculdade de Economia da Universidade de Coimbra, 2000.

LOBO, M.M.: "Redes familiares y estrategias de poder en la Misericordia de Monçao durante el siglo XVIII”, Estudios Humanísticos, Historia, no 5, 2006, pp. 121-136.

LÓPES, F.P., y CARDOSO, H.: “Gestao das IPSS com Valencias diversificadas: proposta de um modelo de referencia de actuaçao estratégica dos dirigentes", V Colóquio Ibérico de Cooperativismo e Economia Social, 10-11 de Julho, Santarém, Portugal, 2009.

MONZÓN, J.L.: Economía Social y conceptos afines: fronteras borrosas y ambiegüedades conceptuales del Tercer Sector, CIRIEC-ESPAÑA, Revista de Economía Pública, Social y Cooperativa, $\mathrm{n}^{\mathrm{o}}$ 55, 2006, pp. 9-24.

MOZAS, A., y BERNAL, E.: Desarrollo territorial y economía social, CIRIEC-España, Revista de Economía Pública, Social y Cooperativa, nº 55, 2006, pp. 125-140.

NOGALES, M.A.: Desarrollo rural y desarrollo sostenible. La sostenibilidad ética, CIRIECEspaña, Revista de Economía Pública, Social y Cooperativa, nº 55, 2006, pp. 7-42.

OLIVEIRA, P., y SIMÖES, J.: As cooperativas como agentes de empreendedorismo social na era da economía do conhecimento", V Colóquio Ibérico de Cooperativismo e Economia Social, 10-11 de Julho, Santarém, Portugal, 2009.

SAMARTINHO, J., y FARIA, J.: “A E-liderança nos proyectos em empresas de inserçao (EI) de economía social enquanto potenciadora da construçao de pontes para a estratègia de 
emprego e de inclusao social”, V Colóquio Ibérico de Cooperativismo e Economia Social, 10-11 de Julho, Santarém, Portugal, 2009.

SAZ GIL, M M $^{\mathrm{a}}$ I. y CARÚS, L.: Los procesos participativos en la sostenibilidad medioambiental. El caso del segmento turístico recreativo de Alta Montaña, CIRIECEspaña, Revista de Economía Pública, Social y Cooperativa, nº 61, 2008, pp. 127-156.

SUSTAINABILITY: La ONG del siglo XXI. En el mercado por el cambio. Documento realizado por encargo de The Global Compact y de United Nations Environment Programme. Traducido del inglés por Fundación Ecodes con el soporte de Fundación Avina. Original publicado en 2003. 